\title{
Japan tragedy: Five years later
}

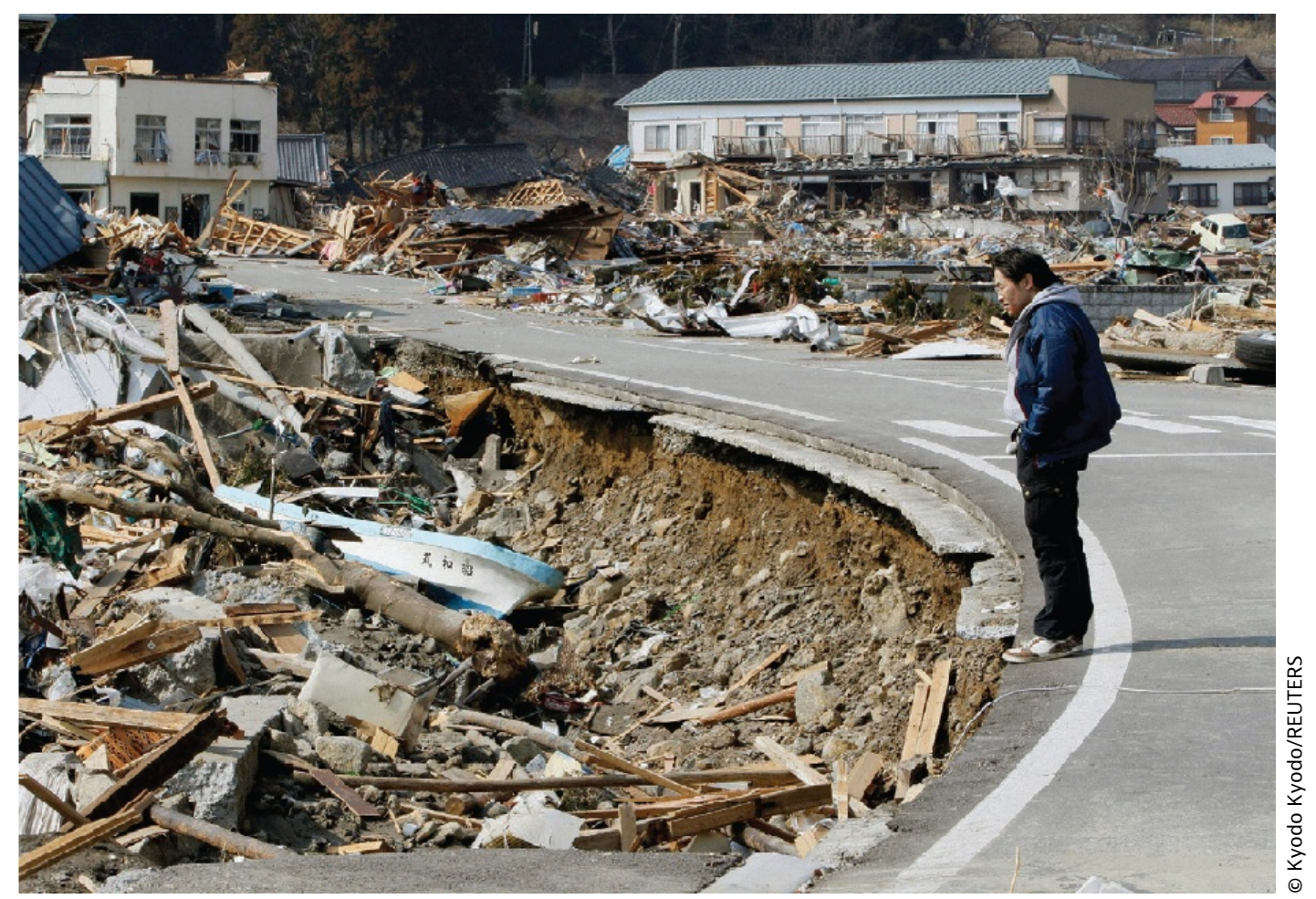

Five years ago, on 11 March 2011, a violent earthquake struck eastern Japan. The tsunami that ensued devastated the inland up to $10 \mathrm{~km}$ and put the Fukushima nuclear power plant at risk, forcing it out of action. The result was a humanitarian and environmental crisis.

The National Police Agency of Japan put the total death toll at 15,894 people, while 2,561 are still missing. Japan is still absorbing the enormity of the disaster, both physically in rebuilding, and emotionally.

"Many people are still leading uncomfortable lives in the affected areas", Prime Minister Shinzo Abe said during his 11 March 2016 memorial address. "We commit ourselves to providing care for their minds and bodies, forming new local communities and supporting industrial development of the affected areas."

OECD Secretary-General Angel Gurría also shared his strong support to the families and communities affected, and underlined his conviction to keep working closely with Japan on this, and many other important issues. "We have 
witnessed unprecedented resilience amongst the Japanese people in these five years. We admire their courage and know that Japan is emerging from the disaster stronger." The OECD helped Japan in the aftermath of the disaster via the OECD Tohoku School Project, Mr Gurría pointed out, and the OECD Nuclear Energy Agency continues to work closely with Japan to improve nuclear safety and regulation. "I said it in 2011 and say it again now-we have absolute confidence in Japan's capacity to overcome the Great East Japan Earthquake and tsunami, building on its unique stock of human capital, financial wealth, technology and discipline."

Brian Keeley, "Fukushima's lessons in recovery", in OECD Observer No 300, Q3 2014, http://oe.cd/NF

Motohide Yoshikawa, Ambassador and Permanent Representative of Japan to the OECD, “Japan: Remembering and rebuilding”, in OECD Observer No 290-291, Q1-Q2 2012, http://oe.cd/UW

See http://www.oecd.org/japan/remembering-the-people-of-japan-messagefrom-secretary-general.htm 